DOI: 10.17707/AgricultForest.61.1.26

\author{
Viorel ION, Adrian Gheorghe BASA, \\ Lenuta Iuliana EPURE, Marin DUMBRAVA, Niculae DINCA ${ }^{1}$
}

\title{
ABOVE-GROUND BIOMASS AT DIFFERENT TRITICALE VARIETIES IN THE SPECIFIC CONDITIONS FROM SOUTH ROMANIA
}

\begin{abstract}
SUMMARY
Crop biomass is more and more of interest as raw material for producing different kinds of energy as it is renewable and contribute significantly to the mitigation of the green house effect. The crop biomass is increasingly used as substrate for producing biogas. In this respect, it is widely appreciated that maize is one of the most important crop for producing biomass which can be used for biogas production. But, together with maize there are other several crops that are suitable for producing biomass that could be used as substrate for producing biogas. Among this crops, there is included the triticale crop, which could provide important yields of biomass at late spring and early summer, depending of the growing area.

The aim of the paper is to present the above-ground biomass yield at different varieties of triticale (Negoiu, Mezin, Cascador, Haiduc, Stil, Gorun 1, Polego, Tulus, Titan, Oda) in some of the most important plant growth stages and in the specific conditions from South Romania. Also, it is aimed to present the results obtained in the medium milk growing stage regarding the share of biomass on plant components, the moisture content of plant components, as well as regarding plant height and stem diameter at soil level. Researches were performed in 2012/2013 in field experiments located in South Romania, on a reddish preluvosoil.
\end{abstract}

Keywords: biomass, triticale, yield, varieties.

\section{INTRODUCTION}

Crop biomass is more and more of interest as raw material for producing different kinds of energy. This is due to the fact that it is renewable and contributes significantly to the mitigation of the green house effect.

The crop biomass is increasingly used as substrate for producing biogas. Apart maize which is one of the most important crop for producing biomass

\footnotetext{
${ }^{1}$ Viorel ION, (corresponding author: viorelion@agro-bucuresti.ro), Adrian Gheorghe BASA, Lenuta Iuliana EPURE, Marin DUMBRAVA, Niculae DINCA, University of Agronomic Sciences and Veterinary Medicine of Bucharest, Faculty of Agriculture, 59 Marasti Blvd, District 1, 011464 , Bucharest, ROMANIA.

Paper presented at the $5^{\text {th }}$ International Scientific Agricultural Symposium "AGROSYM 2014".

Notes: The authors declare that they have no conflicts of interest. Authorship Form signed online.
} 
which can be used for biogas production, there are also some other several crops which are suitable for producing biomass. One of these crops is triticale, which could provide important yields of biomass at late spring and early summer, depending of the growing area. Triticale biomass was firstly of interest as fodder, but it has become also of interest as raw material for producing biogas.

Triticale is a specific crop, which can be used for satisfying energy demand; it is considered as being an energy crop for heating and electricity purposes (De Lucia et al., 2013).

Triticale (Triticosecale Wittmack), a new man made cereal, is known to be more drought tolerant and high yielding; it is a potential cereal to give better yield under moister stressed condition (Mohammad et al., 2011). Triticale has the ability to realize increased grains and biomass yields under various pedoclimatic conditions with limited resources (Ittu et al., 2001). Triticale is able to resist some unfavourable biotic and abiotic environmental factors and thus produce good yield in marginal regions (Martinek et al., 2008; Lalević et al., 2012). The capacity of triticale crop to perform well under limited growing conditions made possible the cultivation of this plant on more than 3 million hectares every year since 2002, according to FAO database, the tendency being to exceed 4 million hectares in the last years.

A number of evidences have shown that triticale produces more aboveground dry matter than other winter cereals in dry environments; triticale advantages were especially noticeable in the Mediterranean-type environment where yield and biomass were almost twice than that of wheat (EstradaCampuzano et al., 2012). Triticale produced on average more above-ground biomass than wheat over a wide range of experiments, but in some situations, triticale and wheat had similar biomass (Bassu et al, 2011). In Romania, the South area provides favourable growing conditions for triticale, which is used both for grain yield and biomass (Dumbrava et al., 2014).

The aim of the paper is to present the above-ground biomass yield at different varieties of triticale in some of the most important plant growth stages and in the specific conditions from South Romania. Also, it is aimed to present the results obtained in the medium milk growing stage regarding the share of biomass on plant components, the moisture content of plant components, as well as regarding plant height and stem diameter at soil level.

\section{MATERIAL AND METHODS}

Researches were performed in 2012/2013 in field experiments located in South Romania, respectively at Moara Domneasca Experimental Farm (44 $30^{\circ}$ ' North latitude and $26^{\circ} 14$ ' East longitude) belonging to the University of Agronomic Sciences and Veterinary Medicine of Bucharest. The field experiments were located on a reddish preluvosoil.

During the nine months of interest for triticale, respectively from September 2012 to June 2013, the average temperature was of $9.3^{\circ} \mathrm{C}$ (the multiannual average temperature for the studied area is $7.5^{\circ} \mathrm{C}$ ). The sum of 
rainfall was of $225 \mathrm{~mm}$ (the multiannual average rainfall for the studied area is $408.9 \mathrm{~mm}$ ), which made the growing conditions to be not so favourable.

Researches were performed at an assortment of 10 triticale varieties, respectively: Negoiu, Mezin, Cascador, Haiduc, Stil, Gorun 1, Polego, Tulus, Titan, and Oda. Each variety was sown on a plot of $144.8 \mathrm{~m}^{2}$ (3.62 m of width and $40 \mathrm{~m}$ of length). The sowing was performed on $16^{\text {th }}$ of October 2012, at $12.5 \mathrm{~cm}$ row spacing, and at a density of 500 germinal seeds $\mathrm{m}^{-2}$. The preceding crop was rapeseed. The fertilization was performed with $86 \mathrm{~kg} \mathrm{ha}^{-1}$ of nitrogen and $40 \mathrm{~kg} \mathrm{ha}^{-1}$ of phosphorus. The weed control was performed by the help of herbicides.

To the studied triticale varieties, determinations were performed in view to establish the fresh and dry above-ground biomass yield on square meter in some of the most important plant growing stages, respectively: beginning of stem elongation, end of heading, medium milk, and fully ripe. For each variety, the plants from 0.25 square meters, respectively two rows of plants on a length of $1 \mathrm{~m}$ were cut at soil level and were weighed immediately in the field. This procedure was performed in four replications for each variety. For each variety and replication, one average plant was taken and separated by its components (leaves, stem, and ear), weighed immediately in the field and then dried in the laboratory in the oven at $80^{\circ} \mathrm{C}$ for 24 hours for determining the dry biomass and moisture content. The plant height and stem diameter at soil level were determined at ten stems for each triticale variety and replication.

The obtained data were statistically processed by analyses of variance (Anova-single factor).

\section{RESULTS AND DISCUSSION}

Fresh above-ground biomass at beginning of stem elongation varied between 676 and $1399 \mathrm{~g} \mathrm{~m}^{-2}$, according to triticale variety, with an average value for the ten studied varieties of $1173 \mathrm{~g} \mathrm{~m}^{-2}$ (figure 1). At the end of heading, fresh biomass varied between 1711 and $2348 \mathrm{~g} \mathrm{~m}^{-2}$, with an average value for the ten studied varieties of $1961 \mathrm{~g} \mathrm{~m}^{-2}$. In the medium milk growth stage of triticale plants, fresh biomass varied between 2174 and $3075 \mathrm{~g} \mathrm{~m}^{-2}$, with an average value for the ten studied varieties of $2685 \mathrm{~g} \mathrm{~m}^{-2}$. At fully ripe stage, fresh biomass varied between 1720 and $2520 \mathrm{~g} \mathrm{~m}^{-2}$, with an average value for the ten varieties of $2077 \mathrm{~g} \mathrm{~m}^{-2}$.

Dry above-ground biomass at beginning of stem elongation varied according to variety between 121 and $276 \mathrm{~g} \mathrm{~m}^{-2}$, with an average value for the ten studied varieties of $199 \mathrm{~g} \mathrm{~m}^{-2}$ (figure 2). At the end of heading, dry biomass varied between 344 and $598 \mathrm{~g} \mathrm{~m}^{-2}$, with an average value for the ten studied varieties of $453 \mathrm{~g} \mathrm{~m}^{-2}$. In the medium milk growth stage of triticale plants, dry biomass varied between 847 and $1189 \mathrm{~g} \mathrm{~m}^{-2}$, with an average value for the ten studied varieties of $1039 \mathrm{~g} \mathrm{~m}^{-2}$. At fully ripe stage, dry biomass varied between 1429 and $1734 \mathrm{~g} \mathrm{~m}^{-2}$, with an average value for the ten studied varieties of $1521 \mathrm{~g} \mathrm{~m}^{-2}$. 


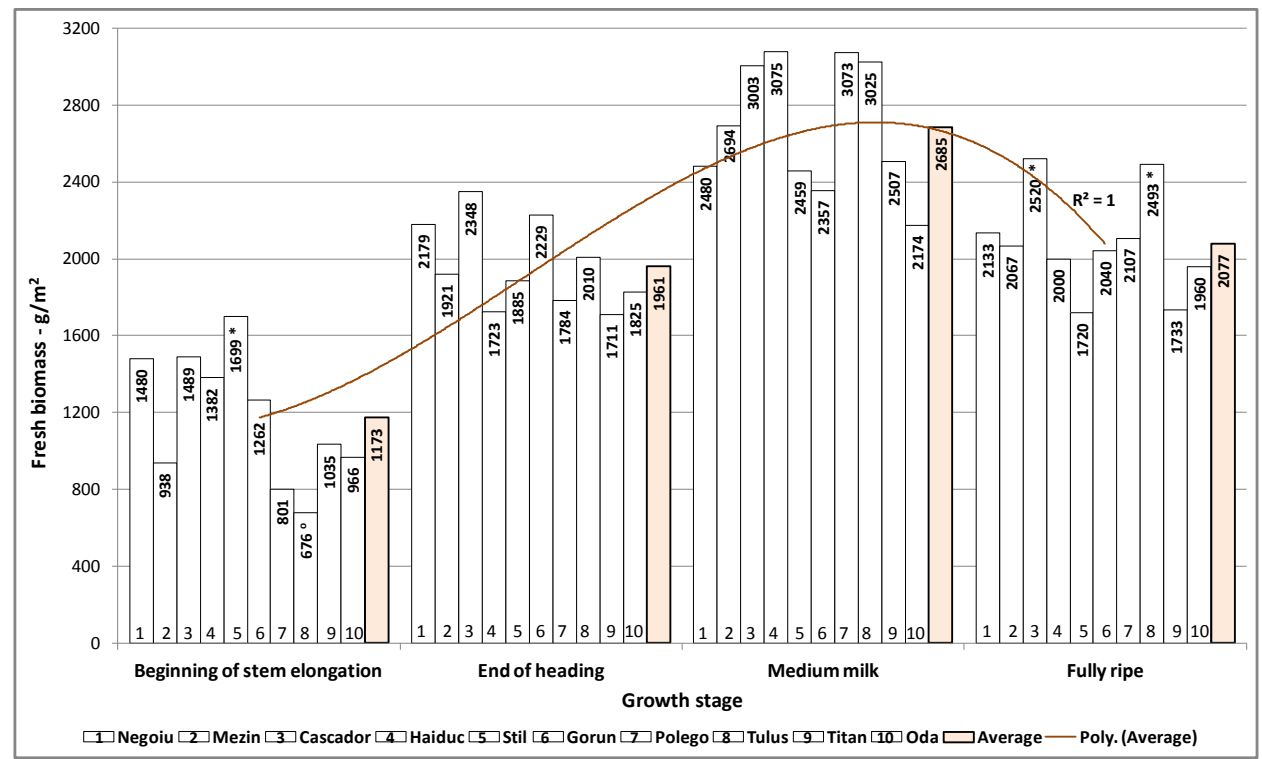

Figure 1. Fresh biomass on square meter at different triticale varieties, in different growth stages of triticale plants, and under the specific conditions from South Romania, in 2013

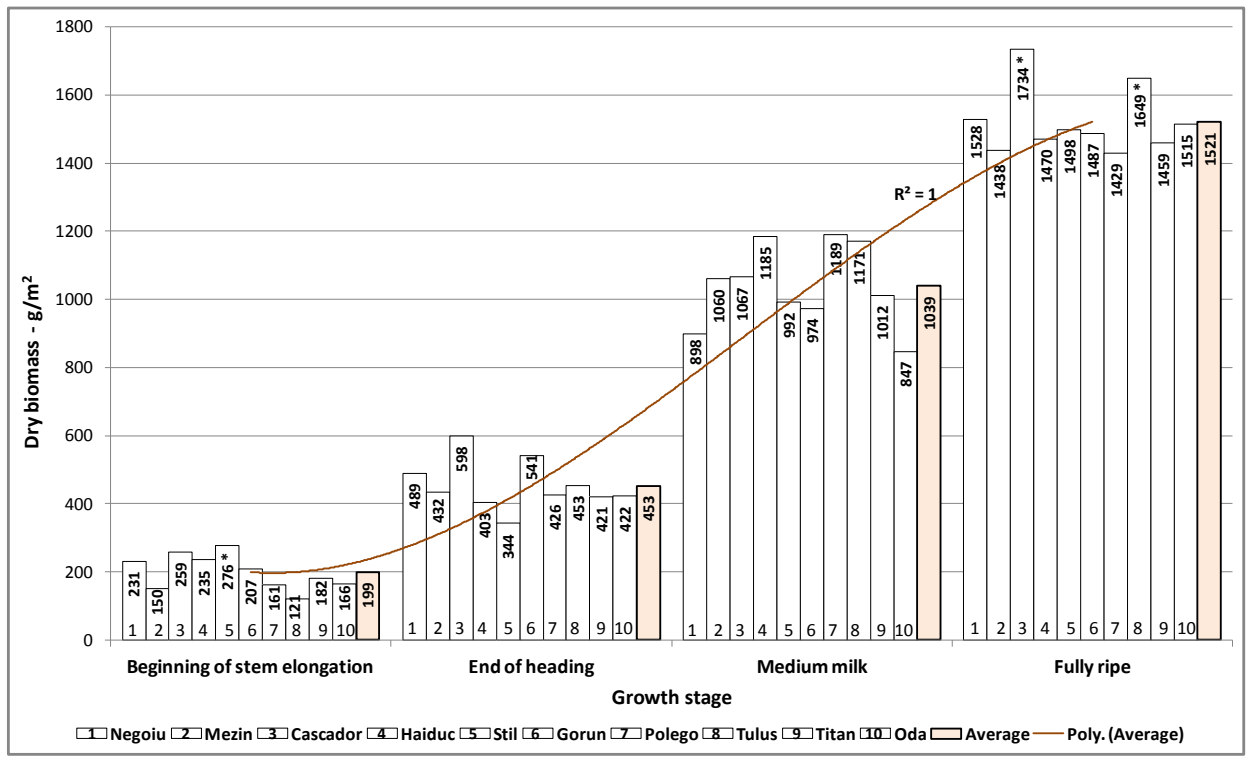

Figure 2. Dry biomass on square meter at different triticale varieties, in different growth stages of triticale plants, and under the specific conditions from South Romania, in 2013 
It is interesting to highlight the fact that each variety had its own rhythm of biomass accumulation and development. Thus, there are varieties which accumulate more biomass in the first growing stages in the spring, while other varieties accumulate more biomass later in the spring and beginning of summer, respectively in the last growing stages. As example, Stil variety accumulated the highest fresh and dry biomass yields among the studied varieties at beginning of stem elongation, with statistically significant differences compared to the average value for the ten studied triticale varieties, but at fully ripe stage this variety registered the smallest fresh biomass yield and a dry biomass yield bellow the average (figures 1 and 2). On the contrary to the situation registered at Stil variety, Tulus variety which registered the smallest biomass yield at beginning of stem elongation, at fully ripe stage registered among the highest values of biomass yields, with differences statistically significant compared to the average value for the ten studied triticale varieties both for fresh and dry biomass. Cascador variety registered from the early growth stages high values of fresh and dry biomass yields and continued to accumulate a high biomass up to maturity, when registered the highest values of fresh and dry biomass yields with differences statistically significant compared to the average value for the ten studied triticale varieties.

Starting with milk growth stage of the triticale plants it becomes of interest the above-ground biomass which could be used as substrate for producing biogas as well as fodder. Amon et al. (2007) recommend that cereals used for biogas production should be harvest in the vegetation stage "grain in the milk stage" to "grain in the dough stage". Among the ten studied varieties, in the medium milk growth stage three of them produced more than 11 tons ha ${ }^{-1}$ of dry biomass, respectively Polego (11.89 tons $\left.\mathrm{ha}^{-1}\right)$, Haiduc (11.85 tons ha ${ }^{-1}$ ), and Tulus $\left(11.71\right.$ tons $\left.\mathrm{ha}^{-1}\right)$. Also, other three varieties produced more than 10 tons ha ${ }^{-1}$ of dry biomass.

At fully ripe stage, when the straws could be of interest for different purposes including biogas production, two varieties produced more than 16 tons $\mathrm{ha}^{-1}$ of dry biomass (Cascador - 17.34 tons $\mathrm{ha}^{-1}$ and Tulus -16.49 tons ha ${ }^{-1}$ ), and other two varieties more than 15 tons ha ${ }^{-1}$.

Moisture content of the above-ground biomass at beginning of stem elongation varied between 79.9 and $84.4 \%$, with an average value for the ten studied varieties of $82.9 \%$ (figure 3 ). At the end of heading, moisture content varied between 74.5 and $81.8 \%$, with an average value for the ten studied varieties of $77.0 \%$. In the medium milk growth stage of triticale plants, moisture content varied between 59.7 and $63.8 \%$, with an average value for the ten studied varieties of $61.3 \%$. At fully ripe stage, moisture content varied between 12.9 and $33.9 \%$, with an average value for the ten studied varieties of $26.1 \%$.

Regarding the share of biomass on leaves, stems and ears in the medium milk growth stage of triticale plants, the highest ration were registered by the stems for fresh biomass and by the ears for dry biomass (figure 4). The share of fresh biomass of leaves varied according to variety between 6.7 and $11.8 \%$, with 
an average value for the ten studied varieties of $9.1 \%$. The share of fresh biomass of stems varied between 43.5 and $49.5 \%$, with an average value for the ten studied varieties of $46.9 \%$. The share of fresh biomass of ears varied between 41.4 and $47.4 \%$, with an average value for the ten studied varieties of $44.0 \%$.

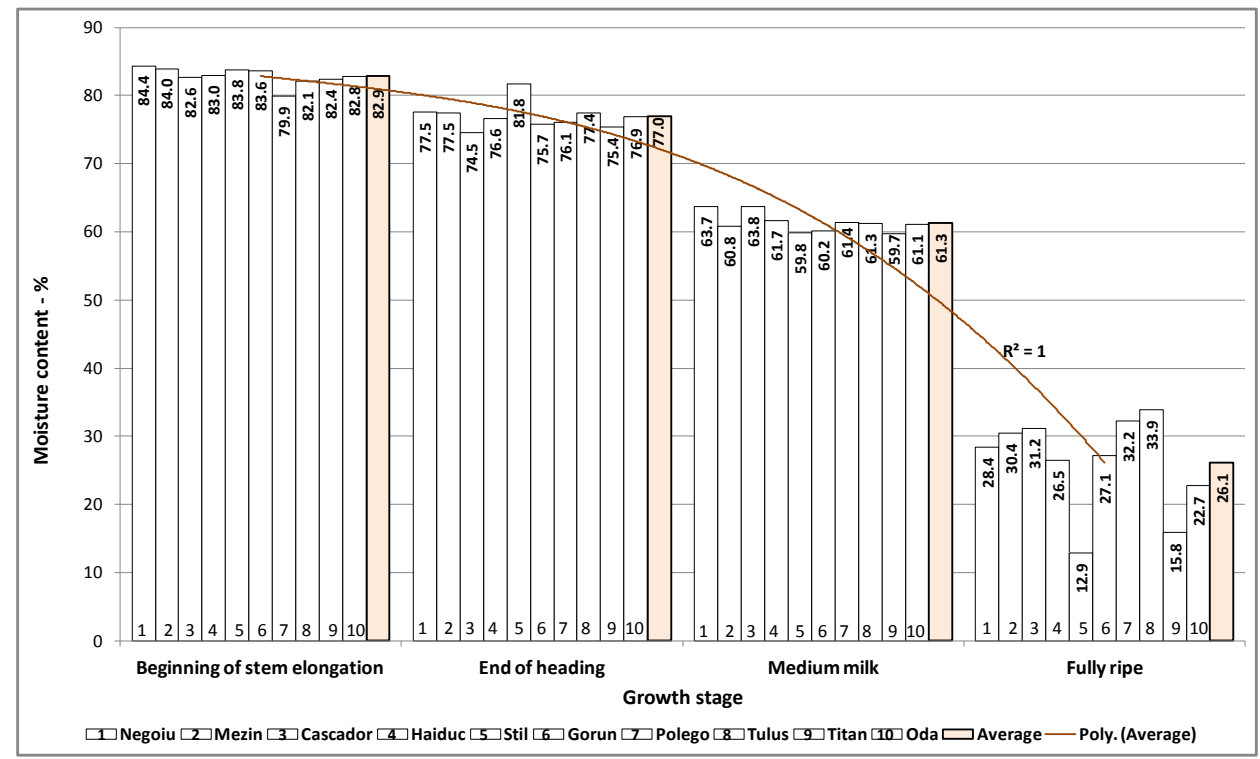

Figure 3. Moisture content at different triticale varieties, in different growth stages of triticale plants, and under the specific conditions from South Romania, in 2013
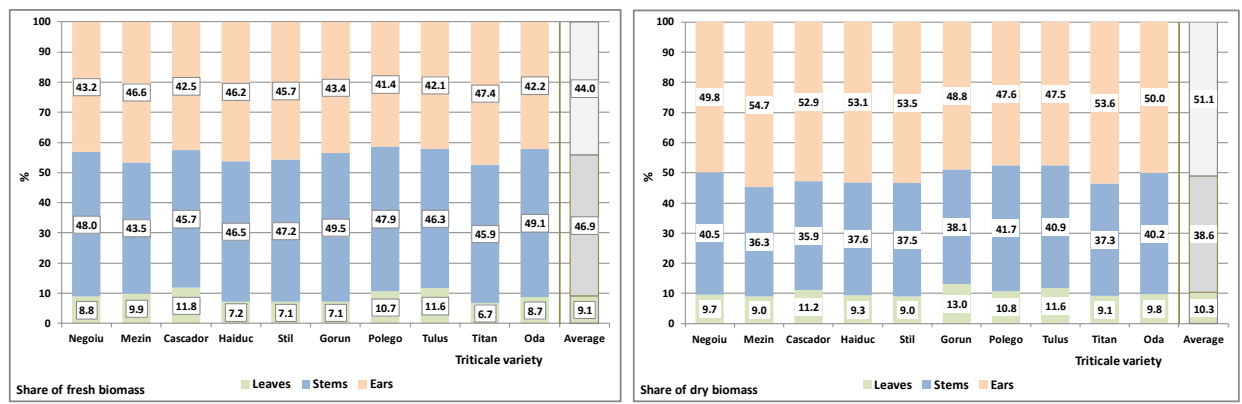

Figure 4. Share of fresh and dry biomass on triticale plant components, at different varieties in medium milk growth stage, and under the specific conditions from South Romania, in 2013

The share of dry biomass of leaves varied between 9.0 and $13.0 \%$, with an average value for the ten studied varieties of $10.3 \%$, the values being higher than those of fresh biomass (figure 4). The share of dry biomass of stems varied between 35.9 and $41.7 \%$, with an average value for the ten studied varieties of $38.6 \%$, the values being smaller than those of fresh biomass. The share of dry 
biomass of ears varied between 47.5 and $54.7 \%$, with an average value for the ten studied varieties of $51.1 \%$, the values being higher than those of fresh biomass.

In the medium milk growth stage of triticale plants, the most humid plants components were the stems while the driest were the ears (figure 5). There are some triticale varieties which had the leaves drier than the ears and on the contrary, to some triticale varieties the ears were drier than the leaves. In average for the ten studied triticale varieties, the moisture content was of $57.7 \%$ for leaves, $68.1 \%$ for stems, and $55.0 \%$ for ears.

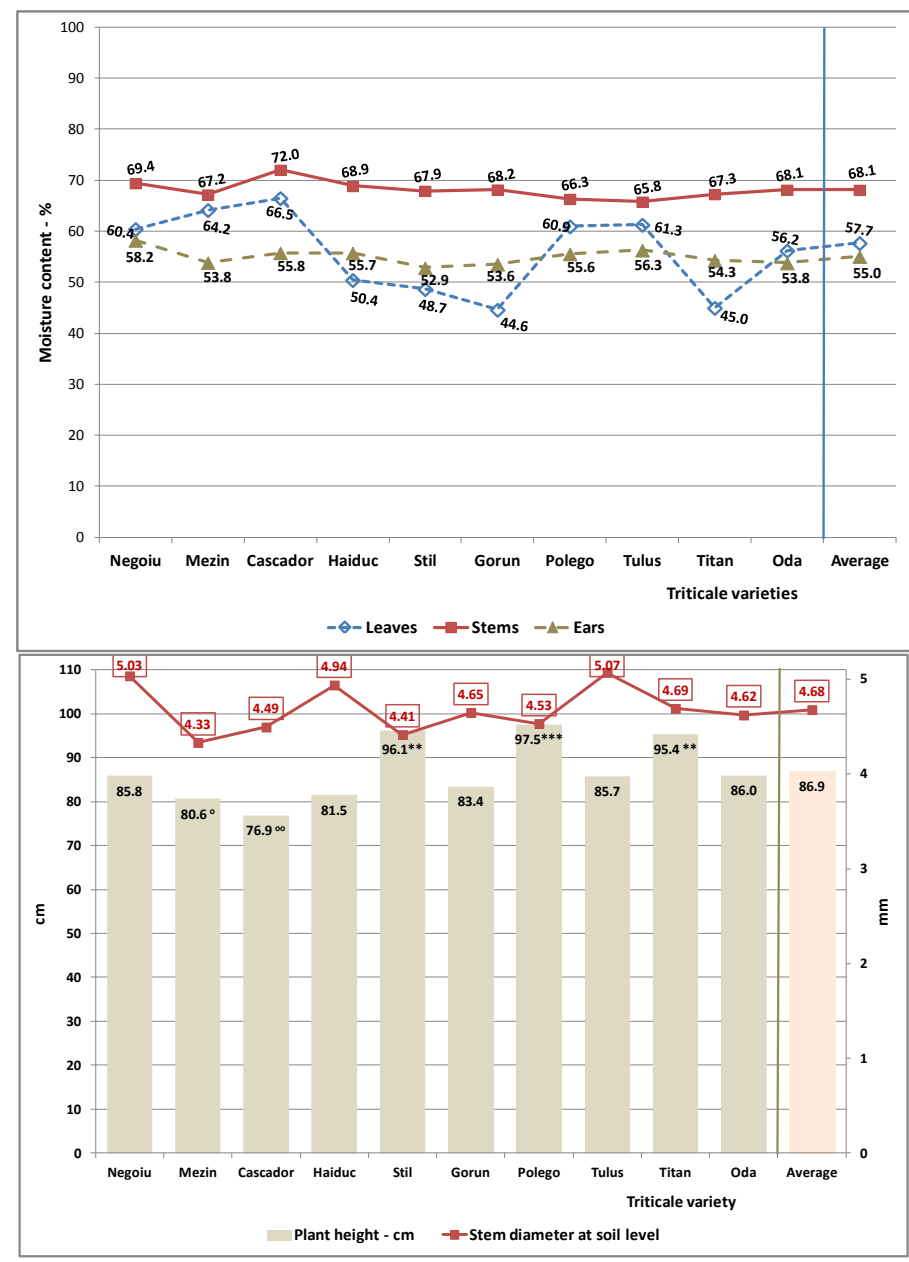

Figure 5. Moisture content of triticale plant components (leaves, stems, and ears), plant height $(\mathrm{cm})$ and stem diameter at soil level $(\mathrm{mm})$, at different varieties in the medium milk growth stage, and under the specific conditions from South Romania, in 2013

The plant height varied between 76.9 and $97.5 \mathrm{~cm}$, with an average value for the ten studied triticale varieties of $86.9 \mathrm{~cm}$ (figure 5). The stem diameter at soil level varied between 4.33 and $5.07 \mathrm{~mm}$, with an average value for the ten studied triticale varieties of $4.68 \mathrm{~mm}$. 


\section{CONCLUSIONS}

In the specific growing conditions from South Romania in 2012/2013, among the ten studied varieties of triticale, in the medium milk growth stage three of them produced more than 11 tons ha ${ }^{-1}$ of dry biomass, while at fully ripe stage two varieties produced more than 16 tons $\mathrm{ha}^{-1}$ of dry biomass. These results show the important potential of triticale to be included into a sustainable energy crop rotation and to be used for biomass production even the growing conditions are not very favourable.

\section{ACKNOWLEDGEMENTS}

The researches carried out for the elaboration of the present paper were financed by Romanian Program "Partnerships for Priority Domains", project PNII-PT-PCCA-2011-3.2-1778 "OPTImization of BIOMass and Approach to Water conservation" (OPTIBIOMA-W), Contract no. 45/2012.

\section{REFERENCES}

Amon T, B. Amon, V. Kryvoruchko, A. Machmüller, K. Hopfner-Sixt, V. Bodiroza, R. Hrbek, J. Friedel, E. Pötsch, H. Wagentristl, M. Schreiner, W. Zollitsch (2007): Methane production through anaerobic digestion of various energy crops grown in sustainable crop rotations. Bioresource Technology, 98: 3204-3212.

Bassu S., S. Asseng, R. Richards (2011): Yield benefits of triticale traits for wheat under current and future climates. Field Crops Research, 124:14-24.

De Lucia C., V. Vecchione, F. Conto, P. Pazienza (2013): The effect of agricultural and energy prices on biomass production: the case of triticale in the OECD area. Intellectual Economics, 7(4): 439-452.

Dumbrava M., A.Gh. Basa, V. Ion, L.I. Epure, N. Dinca, D. Stefan (2014): Results regarding yield and yield components at different triticale varieties. Scientific Papers. Series A. Agronomy, Vol. LVII: 174-179.

Estrada-Campuzano G., G.A. Slafer, D.J. Mirallesa (2012): Differences in yield, biomass and their components between triticale and wheat grown under contrasting water and nitrogen environments. Field Crops Research, 128: 167-179.

Ittu Gh., N.N. Saulescu, M. Ittu, P. Mustatea (2001): Advances in triticale breeding programme from R.I.C.I.C. Fundulea. Romanian Agricultural Research Journal, no 16: 1-6.

Lalević D., M. Biberdžić, M. Jelić, S. Barać (2012): Some characteristics of triticale cultivated in rural areas. Agriculture \& Forestry, 58 (2): 27-34.

Martinek P., M. Vinterová, I. Burešová, T. Vyhnánek (2008): Agronomic and quality characteristics of triticale (X Triticosecale Wittmack) with HMW glutenin subunits 5+10. Journal of Cereal Science, 47: 68-78.

Mohammad F., I. Ahmad, N.U. Khan, K. Maqbool, A. Naz, S. Shaheen, K. Ali (2011): Comparative study of morphological traits in wheat and triticale. Pak. J. Bot., 43(1): 165-170. 